
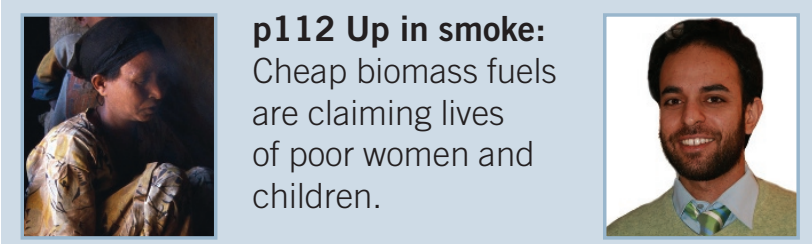

p113 Brainy benefactor: Vikram Kumar has set up a shop to solve public health problems.

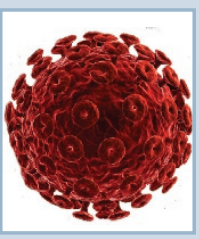

p116 HIV's lair: Damage in the gut reflects the real extent of AIDS's toll.

\title{
Reformed US malaria program garners critics' approval
}

It's been almost two years since the US Congress, spurred by reports that the country's malaria aid programs were hemorrhaging money, took the responsible agency to task for poor accounting and outsize payments to consultants.

The administration seems to have got the message.

US malaria programs now post their budget and contracts on public websites, have shifted more money to spraying insecticides, including DDT, for mosquito control (Nat. Med. 12, 870$871 ; 2006)$, and spend less money on consultants and meetings, according to a December report by the advocacy group Africa Fighting Malaria (AFM), which was among those who excoriated the programs.

"Things are 100-fold better than they were," says Amir Attaran, professor of population health and law at the University of Ottawa, who triggered the congressional scrutiny with several articles in 2004 criticizing the United States Agency for International Development (USAID), which runs the malaria programs. Among his charges were that the agency could not provide detailed audits of its malaria spending (Nature 430, 932-933; 2004).

In May 2005, an AFM report concluded that USAID was spending less than $10 \%$ of its malaria funding on supplies such as drugs, insecticidal bed nets and sprays. The rest of the money went to other costs such as meetings and consultants' fees.

"We didn't particularly like the news," says Admiral Tim Ziemer, who has been chief of USAID's malaria operations since last summer, "but it was accurate."

Responding to the growing scrutiny, the administration in June 2005 launched the $\$ 1.2$ billion five-year President's Malaria Initiative, which is administered through USAID. The initiative last year spent about half of its money on drugs, bed nets and sprays.

Funding for the initiative is projected to be $\$ 300$ million per year from 2008 to 2010 compared with $\$ 80$ million in 2004 and $\$ 14$ million in 1998. The president has asked Congress for $\$ 135$ million for 2007, but it is unclear whether that amount is likely to be approved in a time of tight budgets.

Since the initiative is so new, evidence of its

impact is still being gathered. But AFM says USAID has improved its ability to tally incidence of disease and death.

The agency is also working better with partners such as the Global Fund to Fight AIDS, Malaria and Tuberculosis. "In the past this is not something we had seen a lot of," says Philip Coticelli, an AFM researcher.

Coticelli and others are still concerned that the agency is using many of the same contractors as before. Attaran notes that some contracts on the initiative's website display erased informationincluding total costs and cost ceilings. "There is a sham of transparency here, it's not actual," says Attaran. "There are serious problems that remain."

USAID officials say the agency is trying to strike a

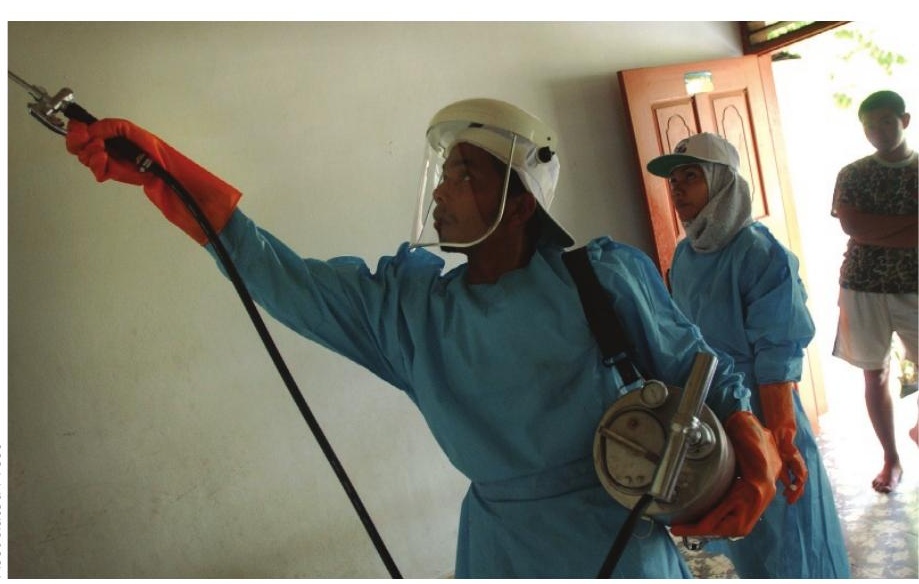

Pest control: The US malaria program is spending up to half its budget on drugs, bed nets and spraying of pesticides such as DDT.

\section{Supplement makers face bitter pill}

The last time US Democrats controlled Congress, in 1994, dietary supplement makers received a huge windfall: a new law that gave them the right to make unproven health claims about their products.

This time around, things don't look quite so rosy for the industry, which has grown from a $\$ 9.5$ billion enterprise in 1994 to a $\$ 22$ billion behemoth.

"We will take a hard look at dietary supplements," Democratic congressman John Dingell, new chairman of the House Energy and Commerce Committee, told reporters the day after the November elections. "You might even find that the Department of Justice will be looking into possible criminal sanctions."

The Dietary Supplement and Nonprescription Drug Consumer Protection Act, signed into law in December, and largely supported by the industry, requires companies to report adverse reactions to the Food and Drug Administration (FDA), but puts the onus on the agency to prove that a supplement is unsafe.

Since 2003, following reports of deaths related to ephedra (Nat. Med. 9, 634-635; 2003), Dingell has tried to push through another bill that would significantly boost the FDA's authority to investigate supplements, even when the agency has not received reports from the companies of bad reactions.

Supplement makers have no incentive to bring dangerous products to market, says Steven Mister, president of the Council for Responsible Nutrition in Washington, a lobbying group for some 80 supplement firms. "Somebody who is in this for the long run is going to take care of their consumers."

Meredith Wadman, Washington DC 